\title{
Adopting MOOCs on Campus: A Collaborative Effort to Test MOOCs on Campuses of the University System of Maryland
}

\author{
Rebecca Griffiths, Christine Mulhern and Richard Spies \\ Ithaka $S+R$ \\ Matthew Chingos \\ Brookings Institution
}

\begin{abstract}
To address the paucity of data on the use of MOOCs in "traditional" postsecondary institutions, Ithaka $\mathrm{S}+\mathrm{R}$ and the University System of Maryland studied the feasibility of repurposing MOOCs for use in hybrid, credit-bearing courses. In this paper we will describe the design of a large-scale study undertaken to examine the use of MOOCs in fourteen campus-based courses, followed by two types of findings: First, we will share quantitative outcomes from students in hybrid sections, comparing students who took MOOCs with those who were taught in a traditional face-to-face manner; second, we will share qualitative findings on the opportunities and challenges presented by the use of MOOCs on campus. Finally, we will reflect on what would need to occur in order for these models to see widespread adoption in the future.
\end{abstract}

\section{Introduction}

When Massive Open Online Courses (MOOCs) first attracted widespread public attention in 2011, some predicted that they would disrupt higher education by replacing traditional classroom lectures or even entire institutions. However, as it became evident that these extreme proclamations were not going to become reality, some investigators turned to more subtle questions of how MOOC content might be incorporated into traditional degree programs and environments that serve mainstream American college students in order to improve student outcomes and/or reduce costs. 
One of the key selling points of MOOCs is the large volumes of data they generate about learners, providing instructors with a better understanding of learner behavior and informing course design. However, these data only tell us about the people who take MOOCs, and evidence reported by edX indicates that most people who participate in MOOCs are not the same as those pursuing degrees in American colleges and universities (Ho et al., 2014). Thus, the learner data from MOOCs tells us little about how typical postsecondary students would fare in these courses.

Some MOOC creators and institutions have experimented with using MOOCs in their existing courses to replace or enhance the lecture material. MOOCs offer high-quality videos from some of the top professors and institutions worldwide, currently at no cost. Therefore, they could be seen as an alternative to creating one's own lecture videos or as a way to convey knowledge on a subject beyond the instructor's own expertise. That said, little is known about how instructors can actually incorporate these materials in their classes, the potential for them to improve the classes, the challenges they bring, and how students respond to them.

\section{Literature Review}

A case study from Vanderbilt University found a fairly positive response from students when a computer science MOOC from Stanford University was embedded in a graduate seminar (Bruff, Fisher, McEwen \& Smith 2013). An experiment at San Jose State University found substantial gains in pass rates for students in sections using an engineering course from MITx compared to the traditional sections of the course (Ghadiri, 2014). However, some differences in the sections and limits on student background data lessen the weight of these findings. Many components of the course were modified in the sections using the MOOC, and students had the same amount of class time. Moreover, detailed analysis of the background characteristics is not available, so we cannot be sure that there were not significant differences in the baseline student populations. Another experiment at San Jose State University (SJSU) with Udacity and introductory math courses found mixed results. Pass rates in online sections were very low, but researchers attributed this at least in part to the targeted student population (Firmin, Schiorring, Whitmer, Willett \& Sujitparapitaya, 2013). They found that students who were matriculated at SJSU were more likely to earn passing grades than nonmatriculated students. Overall, they concluded that the academically at-risk student population involved in this study fared better in face-to-face courses, but still found room for optimism about the potential of the online resources. While these studies provide insight into how MOOCs can be used and some of their impacts on students, each is about a very specific case with a set of qualifications that make it hard to generalize the results to other instructors and institutions that may be able to take advantage of MOOCs in the classroom.

There is some robust research on the use of other online learning materials for undergraduate students that suggests that these types of materials do not appear to harm student outcomes when used in hybrid formats, though certain subgroups of students may perform worse in fully online courses. Bowen, Chingos, Lack, and Nygren (2014) studied the use of Carnegie Mellon's Open Learning Initiative Statistics course in hybrid undergraduate classes and found no significant difference between the hybrid and traditional sections in student pass rates and assessment scores, including for underrepresented minorities, students from low income families, and first-generation college students. Figlio, Rush and Yin (2013) found that student learning outcomes in a traditional lecture-style course were not significantly different than those for students who had access only to the online videos of the same lectures, but they did find that the online-only treatment had negative impacts for some subgroups of students (Hispanics, males, and lower achieving students).

Research focused on community college students and entirely online courses finds that students perform worse in online courses than face-to-face courses, and that the gap in performance between these two modes is larger for some underrepresented minorities, males, and students with lower levels of prior academic achievement (Jaggars, 2012; Johnson \& Mejilla, 2014; Xu \& Jaggars, 2013). It also finds that the performance gap between students in online and face-to-face courses varies by subject, with online courses having the most negative results in social science and professional studies courses (Xu \& Jaggars, 
2013). Findings about the impact of online courses on progression toward an associate degree or transferring to a four-year institution are mixed. A review of the literature by Jaggars in 2012, as well as a report by Jaggars, Edgecombe, and Stacey (2013), suggests that online courses may hurt progression toward a degree; however, more recent work finds that taking online courses improves a student's likelihood of earning an associate degree or transferring to a four-year institution (Johnson \& Mejilla, 2014; Shea \& Bidjerano, 2014). While these studies focus on different types of courses (online instead of hybrid) and different populations of students than our study, they point out important findings for disadvantaged students that deserve further exploration. Unfortunately, much of the online-learning research lacks careful comparisons of students in different course formats in order to determine the true effect of these materials (Means, Toyama, Murphy, Bakia \& Jones, 2010).

Another important issue is what effect course design and implementation have on student outcomes. Jaggars and Xu (2013) developed an online course-quality rubric and explored the relationship between each quality area and student end-of-semester performance in 23 online courses at two community colleges. The results indicate that the quality of interpersonal interaction within a course relates positively and significantly to student grades. Additional analyses based on course observation and interview data suggest that frequent and effective student-instructor interaction creates an online environment that encourages students to commit themselves to the course and perform stronger academically. Again, this study pertains only to online courses; not hybrid formats.

In addition to understanding the impact on student outcomes it is also important to consider whether and how faculty members actually make use of online course materials. A study by Bacow, Bowen, Guthrie, Lack and Long (2012) provided insight into the barriers to adoption of online learning, benefits universities anticipate from these technologies and how they can be molded to fit institutions' needs. The main findings were the need for open and shared data on student learning that can be generated from online learning technologies and the need for sustainable and customizable platforms for delivering online learning instruction. This study was conducted before the creation of MOOCs, but we find many of their findings directly relevant to our experiences with institutions and faculty.

Since millions of dollars continue to be invested in the development of MOOCs, producing hundreds if not thousands of high-quality online courses, we think it is important to understand how these courses might be able to benefit mainstream undergraduate students. In partnership with the University System of Maryland (USM), and with extensive cooperation from Coursera, a team of researchers at Ithaka $\mathrm{S}+\mathrm{R}$, a nonprofit research and advisory service focused on higher education, set out to learn more about potential uses of MOOCs in campus-based settings. The questions we wished to address included the following: How does the use of MOOCs in hybrid courses impact student outcomes? Can these materials be used by faculty members who did not create them? What kinds of implementation challenges arise, and how can they be overcome? How does use of these tools impact time to plan and teach a course?

This paper will describe the study design and data collection methods and then will move to findings in terms of student outcomes and student reactions. Finally, we will briefly discuss the implications of these findings and topics for further research.

\section{Method}

There were two main components to this mixed-methods study: a set of four side-by-side tests using MOOCs in introductory hybrid courses, and 10 case studies. (Three additional side-by-side tests using the Introductory Biology course from Carnegie Mellon's Online Learning Initiative were also a part of the larger study, but we do not include them in these results so that we can focus our analysis on MOOCs.) For the side-by-side tests, we compared outcomes of students in hybrid sections using MOOCs with outcomes of students in traditionally taught sections of the same course. Students were not randomly assigned to different sections: we controlled for student background characteristics, including age, gender, race/ethnicity, year of study, SAT/ACT scores, parental education and family income when analyzing the outcomes (pass rates and common assessments). The case studies explored the use of MOOCs in a variety 
of course formats, disciplines and divisions. For these we did not attempt to measure outcomes, as there was no baseline cohort for comparison.

\section{Procedures}

In order to recruit test cases, Ithaka S+R and USM staff presented the project at each campus to groups of faculty and administrators. We solicited "statements of interest" from faculty members, asking them to declare their interest in participating, identify a course on campus and a MOOC that might work in that context, and describe a goal or problem that might be addressed through use of the online content. These statements were vetted based on several criteria: whether the proposed use of the MOOC was substantial enough to illuminate the research questions, whether there was a compelling reason for the use of the MOOC, and whether we could obtain permission to use the desired MOOC. This required some back-and-forth with Coursera and its partners. Sixteen courses were selected to be part of the study, from an initial response of 30 statements of interest. Two of the courses were later eliminated from the study because we were not able to use the MOOCs upon which they relied.

It is important to note that our group of instructors was self-selected and probably more motivated to teach with online technologies than the average instructor. This selection of instructors may have led to more positive reviews of the experience as well as better outcomes than if the instructors (and courses) had been randomly chosen.

\section{Participants}

Fourteen faculty members who were interested in teaching with MOOCs were recruited from seven institutions across the USM, which included research universities, regional comprehensives, a metropolitan institution, and historically black universities. In all but one instance, Coursera set up local versions of MOOCs, which the USM faculty could customize to meet the needs of their courses and students. In four instances we set up side-by-side tests comparing outcomes of students in traditionally taught sections with those of students in hybrid sections using MOOCs. Three of these had reduced class time.

In addition, we conducted 10 case studies, in which faculty incorporated MOOCs into a variety of small, single-section courses. The tests covered a diverse range of disciplines, including math, statistics, computer science, communications, studio art, poetry, philosophy, nutrition, ancient Greek and Roman mythology, and introductory literature. Sizes ranged from six students up to 60. Instructors used MOOCs to replace some of the course content or enhance the existing course materials. One of these courses was entirely online, and in another students enrolled in the public offering of the MOOC and engaged in parallel seminar discussions and assessments at their own institutions. Several case studies involved firstyear learning communities (linked courses that enroll the same cohorts of students and are intended to reinforce each other).

In total, there were 855 students involved in these tests, including 664 in side-by-side tests and 193 in case studies. We obtained background data for 836 students, and 562 completed final surveys (including those in control sections). We conducted interviews with 19 instructors, some of whom taught different sections of the same course. Tables 1 and 2 provide more details on the courses, students, formats, and outcome measures involved in both the side-by-side comparisons and the case studies.

\section{Data Collection}

For all tests we collected data on student backgrounds, enabling us to analyze survey responses for subgroups of students (such as first-year students). We also conducted student surveys in all tests as well as interviews with all instructors before the beginning of the term and after the conclusion in order to understand how they used the MOOCs in their courses, as well as their experiences and perspectives on what worked and did not work. Most of these data relate to the implementation challenges that arise in embedding MOOCs in campus-based courses. The interviews followed a standard set of questions, and we coded and tabulated categories of comments. 
Table 1 Courses and Students Involved in Side-by-Side Comparisons

\begin{tabular}{|c|c|c|c|c|c|c|}
\hline Course & $\begin{array}{l}\text { Number } \\
\text { of } \\
\text { treatmen } \\
\text { t sections }\end{array}$ & $\begin{array}{l}\text { Students in } \\
\text { treatment } \\
\text { sections }\end{array}$ & $\begin{array}{l}\text { Students in } \\
\text { control } \\
\text { sections }\end{array}$ & $\begin{array}{l}\text { Minutes } \\
\text { per week } \\
\text { treatment } \\
\text { section met }\end{array}$ & $\begin{array}{l}\text { Minutes } \\
\text { per week } \\
\text { control } \\
\text { section met }\end{array}$ & $\begin{array}{l}\text { Outcome } \\
\text { measure }\end{array}$ \\
\hline Statistics & 2 & 64 & 64 & 150 & 150 & $\begin{array}{l}\text { Posttest; } \\
\text { common } \\
\text { final }\end{array}$ \\
\hline Pre-calculus & 2 & 55 & 67 & 120 & 220 & $\begin{array}{l}\text { Posttest; } \\
\text { common } \\
\text { final }\end{array}$ \\
\hline $\begin{array}{l}\text { Computer } \\
\text { science }\end{array}$ & 4 & 92 & 84 & 75-100 & 150 & $\begin{array}{l}\text { Common } \\
\text { midterm }\end{array}$ \\
\hline $\begin{array}{l}\text { Communication } \\
\text { s }\end{array}$ & 4 & 104 & 103 & 80 & 160 & $\begin{array}{l}\text { Posttest; } \\
\text { common } \\
\text { final }\end{array}$ \\
\hline
\end{tabular}

Table 2 Courses and Students Involved in Case Studies

\begin{tabular}{|c|c|c|c|c|}
\hline Course & Format notes & $\begin{array}{l}\text { Number } \\
\text { of } \\
\text { sections }\end{array}$ & $\begin{array}{l}\text { Number } \\
\text { of } \\
\text { students }\end{array}$ & $\begin{array}{l}\text { Minutes per } \\
\text { week they met }\end{array}$ \\
\hline Art & MOOC used for content portion & 1 & 9 & 160 \\
\hline Poetry & Live public offering of the MOOC & 1 & 11 & 150 \\
\hline Genetics & $\begin{array}{l}\text { MOOC used to replace some } \\
\text { lectures }\end{array}$ & 1 & 60 & $75-150$ \\
\hline $\begin{array}{l}\text { Psychology } \\
\text { learning community }\end{array}$ & $\begin{array}{l}\text { MOOC used to replace some } \\
\text { content in two courses }\end{array}$ & 2 courses & 24 & 250 \\
\hline $\begin{array}{l}\text { Information } \\
\text { technology }\end{array}$ & $\begin{array}{l}\text { MOOC replaced middle third of the } \\
\text { course }\end{array}$ & 1 & 19 & $\begin{array}{l}0 \text { or } 150 \\
\text { depending on } \\
\text { week }\end{array}$ \\
\hline Political science & Supplemental & 1 & 11 & 150 \\
\hline $\begin{array}{l}\text { English Learning } \\
\text { Community A }\end{array}$ & $\begin{array}{l}\text { MOOC used as a common } \\
\text { experience across three courses }\end{array}$ & 3 courses & 17 & 210 \\
\hline Philosophy & Summer pilot, entirely online & 1 & 6 & 0 \\
\hline Literature & $\begin{array}{l}\text { Two MOOCs used to provide } \\
\text { greater insight into ancient } \\
\text { mythology }\end{array}$ & 1 & 17 & 150 \\
\hline $\begin{array}{l}\text { English Learning } \\
\text { Community B }\end{array}$ & $\begin{array}{l}\text { MOOC used to provide context to } \\
\text { the literature covered in class }\end{array}$ & 1 & 19 & 150 \\
\hline
\end{tabular}

\section{Side-by-side Comparisons}

Participating institutions provided administrative data related to academic preparation and demographic characteristics for all students in treatment and control groups. Students who consented to participate in the study were asked to complete surveys designed to solicit additional information about their backgrounds (e.g., parental education and family income), as well as interest in the course subject and their experiences in the course. Surveys were conducted in control sections as well as treatment sections. We allowed the institutions discretion over whether to offer small incentives to students for participation, and three tests chose to do so.

Due to the range of courses involved, we could not implement a uniform posttest. Instructors for each course determined what their students should learn and designed assessments according to those standards. We asked treatment and control group instructors to agree on common exams or at least a 
significant subset of common questions on exams, and these are the primary outcome measures. One limitation is that these scores cannot be compared to a benchmark outside of the given university (or course) and are subject to the instructors' discretion of what students should learn. A few instructors also mentioned that slight differences between content in the treatment and control groups may have influenced students' scores (if some content on the assessments was covered more in one section than another) independent of how well students learned the content taught in their sections. We also obtained pass rates and grades, which can be subject to variations in grading standards among instructors. Although no single measure provides a perfect assessment of student performance, we believe that taken together these three measures provide a reasonable assessment of student performance.

\section{Case Studies}

We conducted 10 case studies using MOOCs in courses that did not allow for rigorous evaluation of learning outcomes due to smaller course enrollments. The purpose of the case studies was instead to deepen our understanding of the implementation process, to explore ways that MOOCs could be used to enhance teaching and learning in different types of courses, and to gain insight into student and instructor experiences in a larger set of instances. While instructors have views as to whether student learning benefitted from the use of MOOCs, we cannot compare them to a reference cohort; thus, we do not report passing rates or grades for these courses.

\section{Findings}

This section reports quantitative and qualitative findings from both the side-by-side comparisons and the case studies in order to present a more holistic picture. More detail on the findings and data analyses for each test type can be found in the complete report (Griffiths, Chingos, Mulhern, \& Spies, 2014).

\section{Student Learning Outcomes and Survey Responses}

After controlling for SAT scores, cumulative GPA at the beginning of the semester, race/ethnicity, gender, parental income, and student age, differences between students in hybrid sections and those in traditionally taught sections were not statistically significant at the $10 \%$ level when averaged across the four side-by-side comparison courses (see Figure 1). In other words, the hybrid effect on student outcomes was not statistically different from zero. These outcomes are noteworthy in consideration of the fact that faculty members were teaching redesigned hybrid courses for the first time using new technology, and the fact that hybrid sections had an average of 103 minutes of face-to-face class time per week, compared to 166 minutes for traditionally taught sections. Moreover, we did not see evidence that academically at-risk subgroups of students performed consistently better or worse in hybrid sections, but rather a pattern of small positive and negative effects.

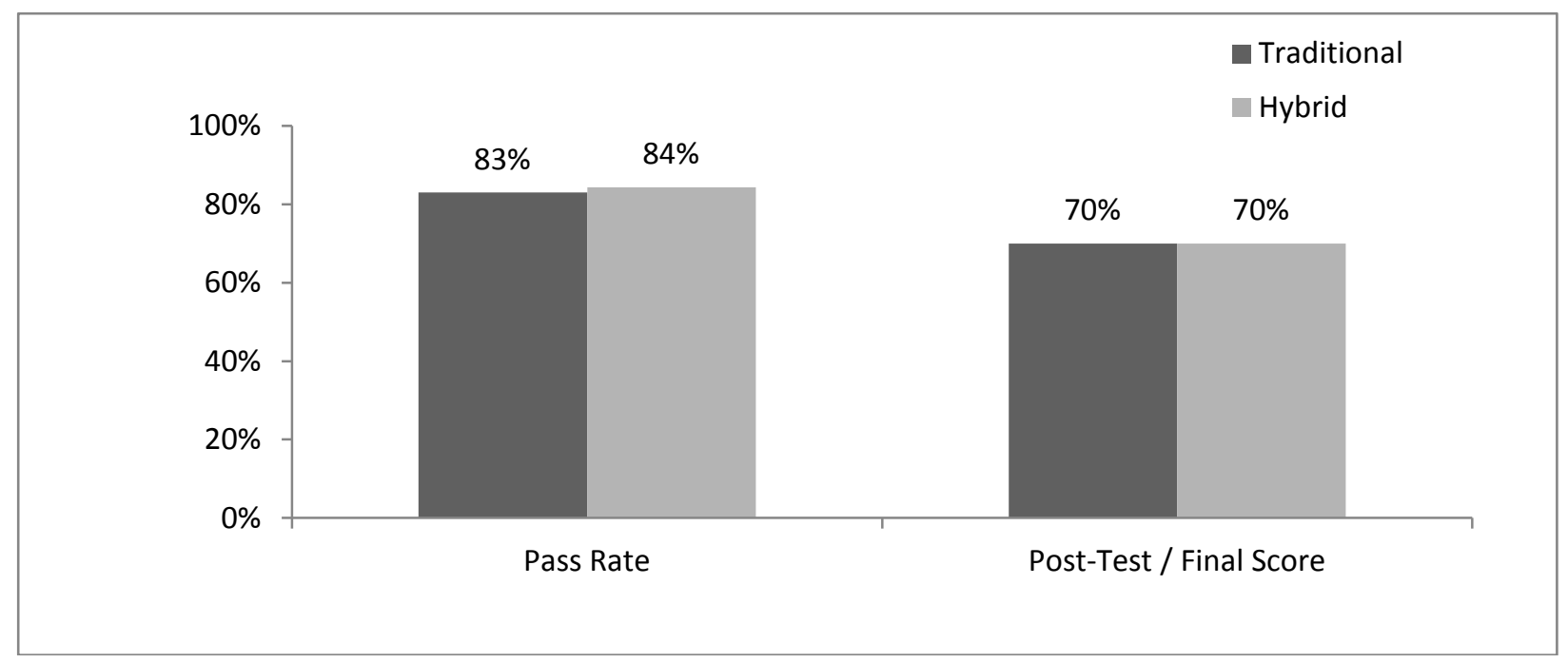

Figure 1. Average posttest/exam scores and pass rates for hybrid versus traditional sections. 
On the other hand, Figure 2 shows that student ratings of the hybrid sections were significantly lower $(p<.05)$ in terms of overall satisfaction and how much they felt they had learned. The impact on their interest in the subject and how difficult they found the course was not statistically significant at the 10\% level. (These ratings are on a five-point scale.) Moreover, students agreed more with the statement "I learned what I needed to in the course primarily from my instructor" than with the statement "I learned what I needed to in the course primarily from Coursera," with respective ratings of 3.7 versus 2.9 (5 means strongly agree while 1 means strongly disagree).

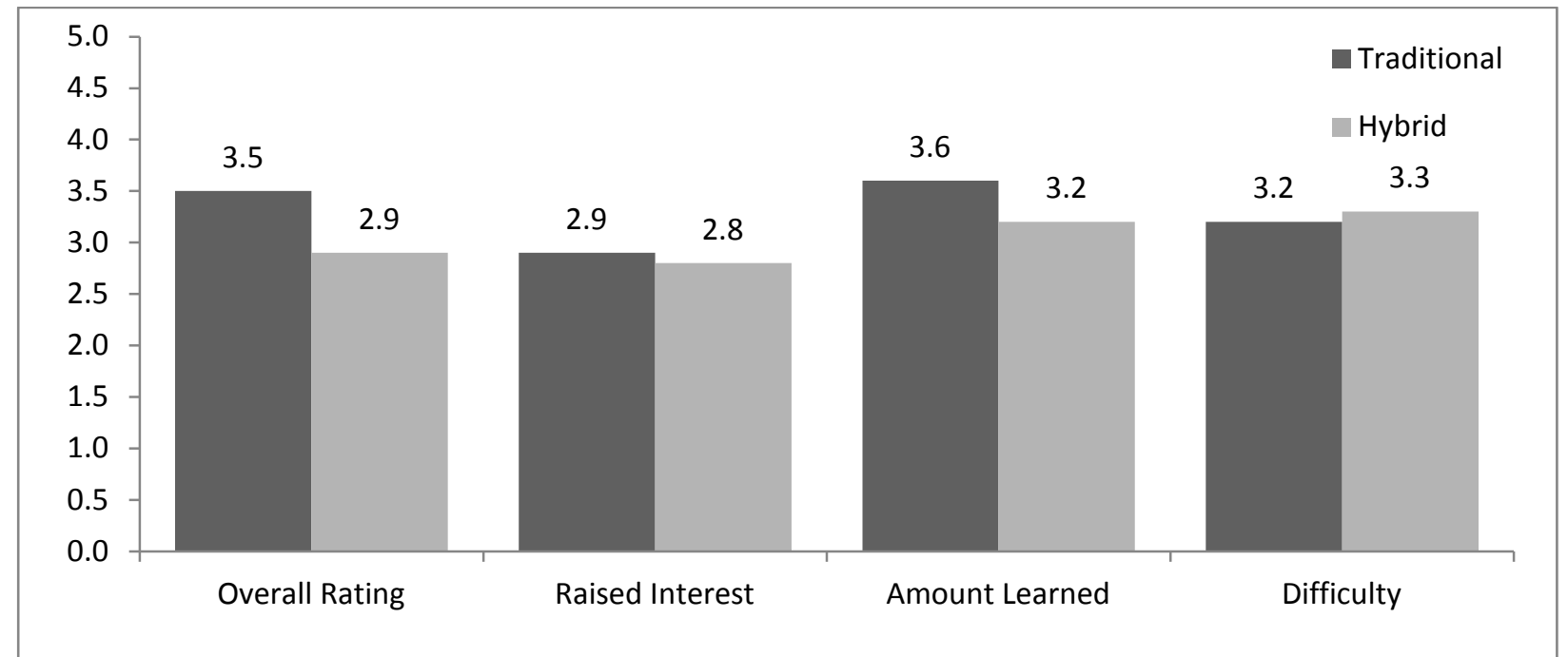

Figure 2. Student survey responses for hybrid versus traditionally taught sections. The differences for Overall Rating and Amount Learned are significant at the $p<.05$ level.

Student ratings of case study courses were somewhat higher, with average overall ratings of $M=$ 3.5 and $M=3.4$ for how much students felt they learned. We have no way to know whether these higher ratings reflect the success of these courses or the characteristics of courses involved in the different types of tests. On average, students gave lecture videos a score of $M=3.3$ for educational value, compared to $M$ $=3.5$ for in-class activities. In side-by-side comparisons, these scores were $M=3.2$ versus $M=3.8$. In half the case studies, students gave higher ratings to the educational value of lecture videos relative to inclass activities, while in the other half we found the opposite responses.

\section{Costs}

One of the most important unanswered questions is whether and how online learning technologies can be used to reduce costs for institutions on a large scale. In this project we could not come close to addressing all the questions we would have liked to answer, but we were able to compile a baseline set of data for the time required to redesign and deliver a hybrid course using readily available online course materials. Faculty time spent on planning and teaching is one of the largest costs associated with a course, and we focused primarily on understanding how this time was spent and the impact of using onlinelearning platforms on amount of time spent.

Faculty members reported investing considerable time redesigning their courses with MOOCs. The time savings that some instructors found during the semester were offset by high up-front time requirements. For the nine instructors who submitted records of the time they spent working on the course, reports ranged from 34 to 248 hours spent on course planning, with a median of 58 and mean of 100 hours. This included time spent watching all the MOOC videos and reviewing assessments, figuring out how to put the pieces together, learning to use the platform, and actually setting up the online components of their courses. Since we did not have the opportunity to repeat the entire set of tests, we do not know how much time would be needed to plan and deliver these courses a second time. About a third of the participating faculty members thought they could save time in the future (see Figure 3). 


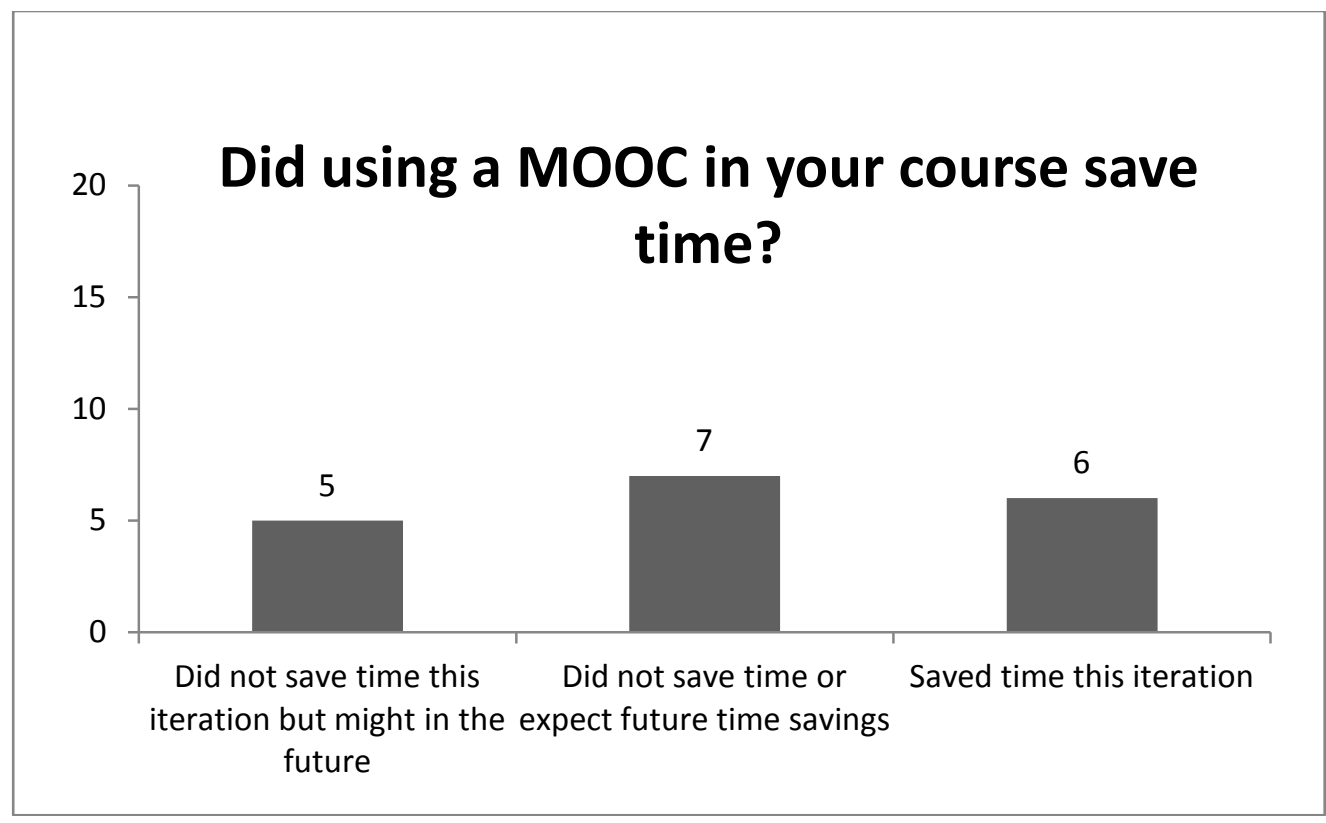

Figure 3. Instructor responses in final interviews.

A key unknown in future cost calculations is the license fee for MOOCs on Coursera. For the purpose of this study, Coursera's partners gave permission to use their courses for free, and Coursera did not charge for its services in setting up and supporting local instances of the MOOCs. It is unlikely that these materials would continue to be available under these conditions.

\section{Faculty Teaching Approaches and Interview Responses}

Participating faculty members identified a number of opportunities for using the MOOC materials to enhance their courses. In all but one case, Coursera set up local instances of MOOCs, enabling instructors to tailor the selection and sequencing of course content, timing, and other elements to fit the needs of their courses. When asked what components of MOOCs they used in their courses, 13 faculty reported that they used multiple components, three faculty used the entire MOOC, and two used videos only.

None of the instructors relied solely upon assessments from the MOOCs, suggesting that these were the element of the MOOCs least well calibrated to the specific needs of each course. All instructors used videos, and several used the embedded quizzes within the videos to track whether students were engaging with the online content. A couple of the instructors required students to submit screenshots of their interactions with the Coursera website to show that they had completed assignments.

\section{Opportunities for enhancement}

Faculty partners identified six types of benefits for students in their hybrid courses using MOOCs. These included the following:

1. Replacing lectures. A pre-calculus instructor chose to use a MOOC in her class because she observed that teaching math at this level through lectures was not effective and she wanted to see whether assigning students to learn new concepts independently and using class time for active problem solving and group work would improve outcomes. In a similar vein, another instructor saw an opportunity to enhance an online introductory philosophy course with online lectures, as she did not have the time or resources to create these materials herself and felt that they would be highly beneficial for students. In both cases, MOOC videos delivered information in a manner similar to that of lectures but did not need to be created from scratch (though, as we saw, redesigning a course using a MOOC still took a lot of time). 
2. Augmenting or replacing secondary materials. One professor used two MOOCs on ancient Greek and Roman mythology in place of textbooks and other secondary sources. Students in the study saved money because they did not need to purchase a textbook (though, as noted above, we do not know how expensive license fees might eventually be for MOOC content or how they would compare to textbook prices). In a different course, an instructor mentioned that students were more likely to watch the videos than read the textbook because a number of students were unwilling to pay for a textbook. Another course used a MOOC to add macroeconomic context to an introductory course in comparative politics. A statistics course used a MOOC to supplement (but not replace) classroom instruction.

3. Filling gaps in expertise. Two instructors were attracted by the possibility of using MOOCs to add expert voices that complemented their own areas of expertise, such as in interdisciplinary programs or survey courses. For example, one professor with a background in information technologies used a MOOC for a module of a human-computer interaction course on product design.

4. Exposing students to other styles of teaching and class discussion. Several faculty members believed that MOOCs could benefit their students by exposing them to different styles of teaching and class discussion. For example, one taught a course on modern poetry and had her students participate in the live offering of a corresponding MOOC, in addition to holding weekly face-to-face class meetings. In the past she had struggled to engage students in critical analysis of texts rather than statements of personal likes and dislikes. The seminar style discussions in the MOOC videos provided a model for her desired style of intellectual discourse. Another team of professors embedded a MOOC on critical reasoning and argumentation into a first-year oral communications course in order to expose students to different teaching styles and personas.

5. Reinforcing key skills, such as critical thinking. A studio arts instructor augmented a course on public art installations with a MOOC on critical reasoning and global challenges. This addition served the dual purpose of teaching students to approach art more analytically and providing a background on issues such as water management and obesity that could be subjects for their art projects. A second instructor integrated a MOOC on nutrition into a program seeking to strengthen basic life skills, such as sleep and eating habits, which have been shown to correlate with student success.

6. Teaching students how to learn online. A professor incorporated a critical reasoning MOOC into a first-year learning community, using it both for its instructional content and as a vehicle for teaching students to become more effective learners. Students viewed MOOC videos together with an undergraduate mentor and discussed strategies for identifying core concepts and effective note-taking.

Faculty partners also identified several ways in which they themselves benefitted from use of MOOCs. One benefit was professional development, as viewing MOOC content afforded an opportunity for instructors to see how other faculty members in their fields teach similar material and, in some cases, to learn new concepts. Another was relief from time pressure during the semester, as most hybrid courses had reduced class time. For example, the professor who used a MOOC to deliver a module of her course on design appreciated the time savings this approach provided during the semester, as she was teaching five different upper level courses at the time. (She found it helpful that she saw many of the same students in other classes during this period, enabling her to check in with them from time to time.)

Finally, three faculty members liked the flexibility to use class time in different ways without the pressure to cover content. For example, a sociology professor, who by his own admission had been slow to adopt instructional technology, reported feeling "excited" and "exhilarated" by the possibility that using MOOCs could enable him to reorient the course from a focus on teaching content (which students could learn online independently) toward "developing a sociological imagination" through project work. He described the technology tools, such as peer review, as "incredibly empowering" for students and felt energized by the opportunity to overhaul the way his course is taught. (This test is not formally part of the MOOCs study because it ended up using Pearson's MySocLabs in the hybrid sections, but the MOOC that was initially under consideration helped to spark many ideas about how the course could be redesigned.) 


\section{Implementation Challenges}

The participants in this study worked through many implementation challenges in order to deliver their courses. Most of these stemmed from the fact that MOOCs on Coursera-as well as the platform itself-were not originally designed to be repurposed for use in other professors' classes, so many modifications were necessary to fit what sometimes felt like "square pegs in round holes." The primary issues encountered were content fit, intellectual property, and technology integration.

1. Content fit. Finding and adapting online content for a hybrid course posed the greatest challenge for faculty partners. MOOCs reflect the priorities of their creators, and these are not necessarily the same priorities that other faculty have for their own students. Moreover, academic departments develop degree program curricula as a whole, making deliberate decisions about when and where certain content should be taught and which competencies should be assessed within specific courses. To integrate a MOOC into an existing class is not necessarily a simple case of choosing what pieces to include or exclude. Even with online course materials that are a fairly close fit with the pedagogical approach of the instructor and needs of the students, the local instructor may need to reconceptualize or restructure his or her existing course to fit with the online content.

About a third of the faculty partners said that the MOOC assumed too high a level of prior knowledge or quantitative skills, while four thought that the assessments did not demand the level of rigor instructors would expect for courses in their institutions. Some faculty members reported that the MOOCs they were trying to use taught concepts in a different way or emphasized different topics than they did in their own approach to teaching a subject. In one course, for example, the USM instructor found that some MOOC units covered topics that would be taught in upper division or graduate courses at his institution. Another found that the lecture videos presented topics in a different sequence than his syllabus, and moreover, that they taught concepts in a cumulative fashion with frequent references to previous units, making it difficult for him to use them out of order. He ended up creating most of the online videos for his hybrid sections and only used around $10 \%$ of the MOOC videos. (This was in a pilot conducted during the spring of 2012 and is not otherwise reported here.)

Content fit was particularly important in introductory courses, which are integral to the curriculum and need to be well matched to the abilities of the student population and requirements of subsequent courses in those programs. Finding a MOOC that was a good fit with an existing course was fairly hit or miss given the small number of options available at the time, and even MOOCs that were reasonably well suited required some customization or "bridging." As a result of these challenges, seven faculty members felt after the study that they could create more appropriate online course materials for their students. All of the instructors participating in this study created their own assessments to go with the MOOCs. In general, we learned that the first generation of MOOCs were structured as coherent narratives, while professors using these materials preferred more flexible modules or "chapters."

2. Intellectual property. During the course planning and delivery period for this study, there was a lot of uncertainty around ownership of MOOCs. In particular, there were questions about whether the IP should belong to the faculty member who created it or to the home institution. Additional questions arose for which there were no clear answers or precedents, such as the following: When an instructor adapts a MOOC for use in a hybrid course, who owns and/or has rights to use the adapted version? What kinds of adaptations should be permitted? Does the instructor who adapted the MOOC have any assurance that these materials will be available for future use? If a new version of a particular MOOC is released, will the instructor be required to use the most recent version, even if that means making adaptations to his or her course all over again? These are critical questions in view of the extensive efforts required to redesign courses using the online materials. For this study we devised ad hoc solutions-and were fortunate to have partners who were willing to participate despite considerable uncertainties as to how these issues would be resolved. It is clear, though, that more standardized policies are necessary to enable large-scale use of these materials in hybrid formats. 
A critical underlying issue is how to balance the instructors' freedom to teach their courses as they wish with the desires of some MOOC creators to monitor or restrict the way their online content is used. The unique value of MOOC materials derives at least in part from their authorship by exceptional professors, and we detected understandable anxiety from several of those approached for this study about losing control of their intellectual creations. Two of these professors expressed concerns about the idea that their courses might be "canned" or repurposed by unknown faculty in other institutions. These worries were by no means universal, however; the majority of Coursera's partners whose permission we sought to include their courses in our study consented readily.

While MOOCs are "open” in the sense of being free to students who enroll in public offerings, they have fairly restrictive terms for other kinds of use. One may not take these courses as part of any kind of tuition-based or credit-bearing course without specific permission, nor is one allowed to modify or repurpose the content in any way. There is currently no standardized way to obtain these permissions.

3. Technology integration. Integrating online learning platforms with campus technology infrastructure presented another set of challenges. The MOOCs used for this study did not "plug" easily into local learning management systems, and thus extensive efforts were required by Coursera and USM staff to support faculty and to enable students to access their local versions of the online course content. Instructors had to work through questions such as the following: Should they embed links to individual videos and online assessments in the campus LMS course page? Should they simply post one link to Coursera and have students navigate their courses within that platform? Or should they download and embed all desired content from Coursera directly into the campus LMS so that students could find all course materials in one place?

Even after these decisions were made, technology integrations did not always go as planned. Although mechanisms were in place in all but one campus to enable "single sign-on" to the online platforms, many students encountered problems accessing the appropriate versions of the MOOCs. One team of instructors that had planned to use an integrated authentication approach abandoned this solution once the course got underway. In survey responses, $21 \%$ of free-text comments about what could be improved in the course concerned technology.

The Coursera platform was not intended to be used by instructors on campus, and thus the features did not meet several of their needs. For example, it was cumbersome to transfer grade information to the local LMS systems, and the peer review feature did not work well for small groups of students. One instructor observed that the Coursera dashboard did not work well for a campus-based course, as she could not monitor the progress of individual students.

Finally, these technology integration issues resulted in incomplete usage data. Many students accessed Coursera through multiple accounts or in other ways that prevented us from keeping close track of individual usage. While data from some courses may be complete, uncertainty about how students were accessing the system mean our data are generally unreliable.

4. Faculty experience. Overall, the faculty members who participated in the study gave overwhelmingly positive reviews of their experiences. Of 19 instructors who participated in final interviews, 15 said they would like to teach again using MOOCs, and an additional three said they might under certain circumstances. Roughly the same numbers said they would recommend this approach to teaching courses to their colleagues. These responses are not entirely surprising given that most of them had volunteered to participate in the study. Still, it may be indicative of some of the benefits instructors found in using MOOCs that were discussed above.

\section{Overall Assessment}

About three quarters of the instructors involved reported that they felt they achieved what they had hoped in their courses using MOOCs. Those who wished to expose students to different styles of class discussion were particularly positive about what they observed in their classes. For example, the instructor of the modern poetry course thought her students pushed themselves to make more analytical comments than in past offerings of the course. Her favorite part of the course was a series of sessions in 
which she videotaped class discussions with students acting as facilitators, thereby producing her own set of MOOC-like videos. Another instructor reported that her students demonstrated a stronger understanding of how to build an argument than she had seen in the past. Instructors who taught an oral communications course reported that students took time to get used to the styles of professors teaching a MOOC, but they saw this as a valuable experience for students who were accustomed to a homogenous learning environment.

A professor who used two MOOCs to replace secondary source materials was extremely pleased with the results. He thought the MOOC videos provided a more accessible and engaging way to deliver technical information than textbooks. His perception was corroborated by surveys, as his students rated the lecture videos as the most valuable component of the course.

Experiments were least successful when the topic of the MOOC was not closely linked to the campus-based course. One instructor had hoped to broaden the scope of his course by incorporating a MOOC that was not tightly coupled and students appear not to have engaged with either the in-class or online components of the course. In another case study, one student wrote in a free-text response saying she did not understand how the MOOC related to other parts of the course.

We also did not find any benefits to students in a statistics course that supplemented traditional instruction with a MOOC without reducing class time. The instructors observed that students did not expect material covered only in the MOOC to be included on tests, and as a result they skipped over it. One instructor speculated that students approached course content from a utilitarian perspective: If watching all the MOOC videos counted for a small number of points relative to less time-consuming activities, they focused their efforts elsewhere.

\section{Limitations}

Our methodology carried some important limitations. Perhaps the most important is that we were not able to repeat the side-by-side tests a second time to see whether instructors might obtain better results with more experience. Similarly, these tests were conducted with MOOCs available in summer 2013. It is reasonable to expect that the technical and pedagogical quality of these materials has improved with time and experience. In the future, we recommend conducting tests such as these over multiple iterations to provide formative as well as summative findings on the use of these technologies and to assess benefits to students and faculty over time.

In addition, we did not attempt to randomly assign either students or instructors to treatment and control sections. Our detailed analysis of background characteristics (available in the full report) indicates that the two cohorts of students were extremely similar and gives us some confidence that selection bias was not an important factor driving our results. While we attempted to control for some instructor background characteristics, such as academic rank, it is possible that treatment group instructors differed in unobservable characteristics, such as motivation. As noted earlier, the posttests were created by local faculty in the Maryland system in accordance with the demands of their programs. We were not able to identify suitable nationally recognized instruments with which to validate their assessments of learning outcomes.

Finally, it would be very difficult for others to replicate the implementations used in this study. Instructors were given considerable latitude to design their courses using MOOCs, and the case studies in particular involved an idiosyncratic mix of course topics and contexts. In future work it would be beneficial to narrow the range of variables in order to provide more conclusive evidence about the impact of key design decisions.

\section{Conclusion}

This study finds that MOOCs can be used to replace some amount of class time without harming students in terms of test score and pass rates. We found that students in the hybrid sections relied heavily on the time they did have with professors, and that those in side-by-side tests reported lower levels of 
satisfaction and felt that they learned less. This finding is consistent with other large-scale studies (Bowen et al., 2014; Figlio et al., 2013; Joyce, Crockett, Jaeger, Altindag \& O’Connell, 2014) and may suggest a higher perceived value of classroom time. The variation of student responses across our set of test cases suggests that student reactions to hybrid formats may depend on the nature of the course, the quality of the online materials, and how effectively they are integrated into the course.

Our qualitative analysis indicates that there are a number of potential benefits for both students and faculty members associated with use of MOOCs, including flexibility in the use of class time, enhanced critical analysis skills, and exposure to different types of teaching styles and class discussions. Surveys indicate that students found value in the online resources, though slightly less than in the in-class activities. One instructor argued strongly that faculty members should take advantage of all tools and resources available to them to improve education given all the challenges they face with students. Most participants said they would like to teach again with MOOCs and would recommend this approach to their colleagues.

At the same time, the conditions are not yet in place to enable adoption of these models on any significant scale. We do not see signs that MOOC providers (either platforms or content creators) are developing business models to support institutional licensing, and we observe that intellectual property provisions still prohibit use of MOOCs in credit-bearing courses without special permission. Technology integration is still a largely manual process. Any faculty member who did have an interest in using these materials in his or her course would be hard pressed to figure out how to do so. Moreover, few universities provide incentives or support for faculty members to use MOOCs—or other types of existing online courseware-in any systematic way.

The path of least resistance seems to be for MOOC providers to serve unaffiliated learners and for faculty members teaching blended courses to rely upon other types of online resources or to create online materials themselves. From a system-wide perspective, this outcome would be unfortunate given the resources being invested in MOOCs and our national imperative to graduate more students from college. If students did as well in courses using very early MOOCs in spite of the many hurdles they and their professors had to overcome in this experiment, how might they fare using more advanced MOOCs, or MOOCs that were a better fit for their courses? Would faculty members take advantage of them if they had adequate rights, incentives, and support? These questions merit further exploration.

\section{Acknowledgements}

This study would not have been possible without the support and cooperation of many individuals and institutions who shared our desire to learn about the implications of using these emerging technologies in campus settings. First, we would like to acknowledge our partners at the University System of Maryland. M. J. Bishop's contributions throughout the project were invaluable, and Jennifer Frank, Don Spicer, Nancy Shapiro, and Lynn Harbinson were instrumental in helping to coordinate with faculty and staff at each institution. The leadership of Chancellor William "Brit" Kirwan and Senior Vice Chancellor for Academic Affairs Joann Boughman was crucial to gaining administrative and faculty support. Graduate Assistants Harish Vaidyanathan and Elizabeth Tobey helped to navigate technical problems and assemble diverse sets of data. Our faculty partners across the system inspired us with their courage in trying new teaching approaches under a spotlight and their willingness to adapt in the face of numerous challenges. These include Megan Bradley, Shoshana Brassfield, Ron Gutberlet, Amy Hagenrater-Gooding, Veera Holdai, Wanda Jester, Adrian Krishnasamy, Courtney Lamar, Velma Latson, Gina Lewis, Theresa Manns, John McMullen, Robert Moore III, Alan Neustadtl, Pamela O’Brien, John O’Rorke, Joseph Pitula, Allissa Richardson, Richard Seigel, Michael Shochet, Tatyana Sorokina, Daryl Stone, Sarah Texel, Johnny Turtle, Barbara Wainwright, Larry Wimmers, Marguerite Weber and Wendy Xu. 
Also essential was the collaboration with Coursera, which agreed to participate in this project at an early stage of its existence, and its institutional partners. We are especially grateful to Daphne Koller and Connor Diemand-Yauman for their support. The faculty and administrators at partner institutions who gave us permission to use their newly hatched MOOCs in our study deserve special attention. These include Walter Sinnott-Armstrong and Ram Neta (Duke University), Celine Caquineau and Mayank Dutia (University of Edinburgh), Sarah Eichhorn and Rachel Lehman (University of California Irvine), Al Filreis (University of Pennsylvania), Jeffrey Borland (University of Melbourne), Mohamed Noor (Duke University), Jamie Pope (Vanderbilt University), Scott Rixner and Joe Warren (Rice University), Jeffrey Rosenthal and Alison Gibbs (University of Toronto), Peter Struck (University of Pennsylvania), Andrew Szegedy-Maszak (Wesleyan University), Karl T. Ulrich (University of Pennsylvania), Walter SinnottArmstrong and Ram Neta (Duke University), and Dave Ward, Duncan Pritchard, Suilin Lavelle, Matthew Chrisman, Allan Hazlett, Michela Massimi and Alasdair Richmond (University of Edinburgh).

This work would not have been possible without generous funding from the Bill and Melinda Gates Foundation and the flexibility we were given to guide the project in a rapidly changing external environment.

Finally, we are grateful to Ithaka S+R's senior advisors who helped to shape this effort, including Lawrence Bacow, William G. Bowen, Kevin Guthrie and Deanna Marcum.

\section{References}

Bacow, L. S., Bowen, W. G., Guthrie, K. M., Lack, K. A., \& Long, M. P. (2012, May). Barriers to adoption of online learning systems in U.S. higher education. Ithaka S+R. Retrieved from http://www.sr.ithaka.org/research-publications/barriers-adoption-online-learning-systems-ushigher-education

Bowen, W. G., Chingos, M. M., Lack, K. A., \& Nygren, T. I. (2014). Learning online at public universities: Evidence from a six-campus randomized trial. Journal of Policy Analysis and Management, 33(1), 94-111.

Bruff, D. O., Fisher, D. H., McEwen, K. E., \& Smith, B. E. (2013). Wrapping a MOOC: Student perceptions of an experiment in blended learning. MERLOT Journal of Online Learning and Teaching, 9(2), 187-199.

Figlio, D., Rush, M., \& Yin, L. (2013) Is it live or is it Internet? Experimental estimates of the effects of online instruction on student learning. Journal of Labor Economics, 31(4), 763-784.

Firmin, R., Schiorring, E., Whitmer, J., Willett, T., \& Sujitparapitaya, S. (2013). Preliminary summary SJSU augmented online learning environment pilot project. The Research \& Planning Group for California Community Colleges. Retrieved from http://www.sjsu.edu/chemistry/People/Faculty/Collins_Research_Page/AOLE Report -September 102013 final.pdf

Ghadiri, K., Qayoumi M. H., Junn, E., Hsu, P., \& Sujitparapitaya, S. (2014). The transformative potential of blended learning using MIT edX's 6.002x online MOOC content combined with student teambased learning in class [edX working paper]. Retrieved from https://www.edx.org/sites/default/files/upload/ed-tech-paper.pdf

Griffiths, R., Chingos, M., Mulhern, C., \& Spies, R. (2014, July 10). Interactive online learning on campus: Testing MOOCs and other platforms in hybrid formats in the University System of Maryland. Ithaka $S+R$. Retrieved from http://www.sr.ithaka.org/researchpublications/interactive-online-learning-on-campus

Ho, A. D., Reich, J., Nesterko, S., Seaton, D. T., Mullaney, T., Waldo, J., \& Chuang, I. (2014). HarvardX and MITx: The first year of open online courses [HarvardX and MITx Working Paper No. 1]. Retrieved from http://ssrn.com/abstract=2381263 or http://dx.doi.org/10.2139/ssrn.2381263 
Jaggars, S. S. (2012). Online learning in community colleges. In Michael G. Moore (Ed.) Handbook of distance education (3rd ed.), 594-608. New York: Routledge.

Jaggars, S. S., Edgecombe, N., \& Stacey, G. W. (2013). What we know about online course outcomes. Community College Research Center, Teachers College, Columbia University, April 2013, 1-8.

Jaggars, S. S., \& Xu, D. (2013). Adaptability to online learning: Differences across types of students and academic subject areas [CCRC Working Paper No. 54]. New York, NY: Community College Research Center, Teachers College, Columbia University.

Johnson, H., \& Cuellar Mejilla, M. (2014). Online learning and student outcomes in community colleges. Public Policy Institute of California.

Joyce, T. J., Crockett, S., Jaeger, D. A., Altindag, O., \& O’Connell, S. D. (2014, March). Does classroom time matter? A randomized field experiment of hybrid and traditional lecture formats in economics. NBER working paper No. 20006.

Shea P., \& Bidjerano, T. (2014). Does online learning impede degree completion? A national study of community college students. Computers and Education, 75(2), 103-111.

Veeramachaneni, K., Dernoncourt, F., Taylor, C., Pardos, Z., \& O’Reilly, U. M. (2013, June). MOOCDB: Developing data standards for MOOC data science. In AIED 2013 Workshops Proceedings Volume (p. 